\author{
FEDERAL RESERVE BANK OF SAN FRANCISCO \\ WORKING PAPER SERIES
}

\title{
The Future of U.S. Economic Growth
}

\author{
John G. Fernald, \\ Federal Reserve Bank of San Francisco \\ Charles I. Jones, \\ Stanford GSB and NBER
}

January 2014

Working Paper 2014-02

http://www.frbsf.org/economic-research/publications/working-papers/wp2014-02.pdf

The views in this paper are solely the responsibility of the authors and should not be interpreted as reflecting the views of the Federal Reserve Bank of San Francisco or the Board of Governors of the Federal Reserve System. 


\title{
The Future of U.S. Economic Growth
}

\author{
John G. Fernald \\ Charles I. Jones* \\ Federal Reserve Bank of San Francisco Stanford GSB and NBER \\ January 14, 2014 - Version 1.0
}

\begin{abstract}
Modern growth theory suggests that more than $3 / 4$ of growth since 1950 reflects rising educational attainment and research intensity. As these transition dynamics fade, U.S. economic growth is likely to slow at some point. However, the rise of China, India, and other emerging economies may allow another few decades of rapid growth in world researchers. Finally, and more speculatively, the shape of the idea production function introduces a fundamental uncertainty into the future of growth. For example, the possibility that artificial intelligence will allow machines to replace workers to some extent could lead to higher growth in the future.
\end{abstract}

* Prepared for the AEA Annual Meetings session on "What's Natural? Key Macroeconomic Parameters After the Great Recession.” We are grateful to Susanto Basu, Bart Hobijn, and Pete Klenow for helpful comments and discussion and to Bing Wang for excellent research assistance. 
Figure 1: U.S. GDP per Person

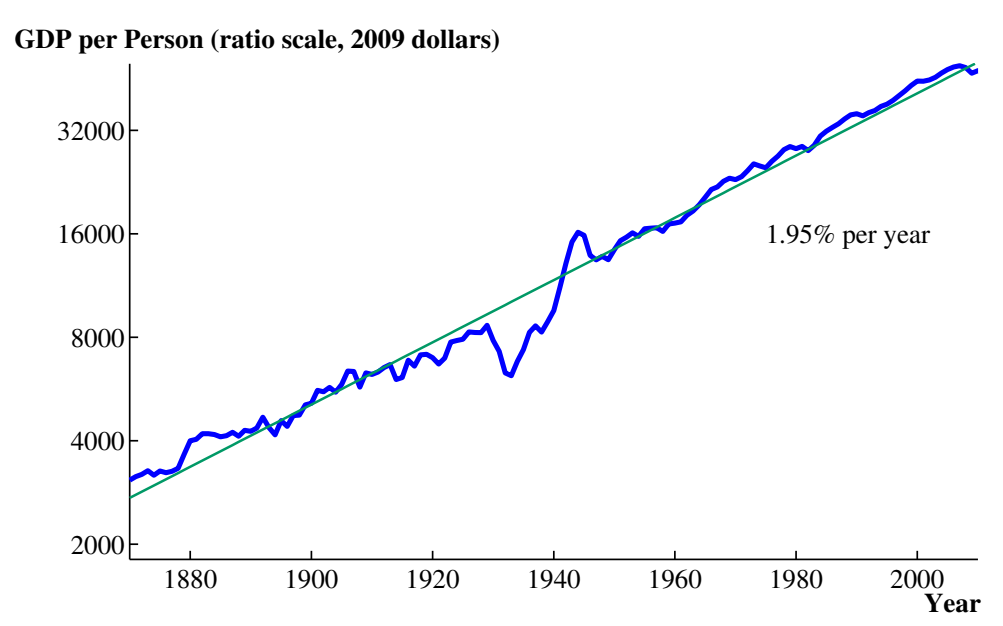

Data for 1870 to 1929 are from Maddison (2008). Data for 1929 to 2012 are from the Bureau of Economic Analysis

\section{Introduction}

Arguably the most important fact of the last century is the steady rise in living standards throughout much of the world. Will this rise continue? We discuss what modern growth theory has to say about economic growth in the United States over the next 25 to 50 years.

\section{The Facts}

Figure 1 shows GDP per person for the United States between 1870 and the present. The stability of the growth rate is remarkable and surprising, with GDP per person lying close to a linear time trend with a slope of just under 2 percent per year. Even the Great Depression was a persistent but not permanent deviation. A tempting conclusion from this figure is that a good guess for future growth is around 2 percent per year.

Despite the impressive fit of a linear trend, growth has at times deviated noticeably from a 2-percent baseline. Visually, for example, it is clear that growth was 
slower pre-1929 than post-1950. Between 1870 and 2007 (to exclude the Great Recession), growth was 2.03 percent per year. Before 1929, growth was a quarter point slower (1.76), while since then it has been a quarter point faster (2.23). ${ }^{1}$ Growth from 1950 to 1973 was faster still (2.50), but then slowed markedly until 1995 (1.82).

The U.S. experience may also understate uncertainty about the future, since other countries have often seen level as well as growth rate changes. Early in the 20th century, for example, the U.K. was substantially richer than the United States; by 1929 , the situation was reversed.

Japan's experience since 1990 — and the financial crisis and Great Recession more recently - raises a related concern. Standard growth theory implies that a financial crisis should not have a long-term effect on income per person: if the rate of time preference and the other parameters of the economic environment are unchanged, the economy should eventually return to its original steady state. This insight is strongly supported by the U.S. experience following the Great Depression, as shown in Figure 1. Despite the large negative shocks of 1929 and the 1930s, the Great Depression was, in the end, temporary - the economy returned to its balanced growth path. However, this logic has failed dramatically in the case of Japan after 1990. Japanese GDP per capita peaked at 86\% of the U.S. level in 1995 and has since fallen to $75 \%$. This observation, which is not easy to understand in terms of the theory we lay out next, is an important cautionary reminder about growth projections.

\section{Accounting with Modern Growth Theory}

We now turn to a version of growth accounting suggested by the semi-endogenous growth model of Jones (2002), in which long-run growth arises from the discovery of new ideas. Final output depends on physical capital $K$, hours worked $N$, human capital per person $h$, and the stock of ideas $A: Y=K^{\alpha}(A h N)^{1-\alpha}$. Traditional growth accounting, following Solow (1957), calculates $A$ as a residual. Modern growth the-

\footnotetext{
${ }^{1}$ The faster post-1929 growth partly reflects changes in measurement: better price deflators and including some intellectual investments as final output.
} 
ory explains that residual in terms of economic forces.

Embedded in this production function is the key insight of Romer (1990): the nonrivalry of ideas leads to increasing returns. As a result, income per person depends on the total number of ideas, not on ideas per person. This contrasts sharply with capital or other rival inputs. Adding one new tractor to the economy benefits one farmer. Adding one new idea potentially benefits everyone, regardless of the size of the economy, because the idea is not depleted with use.

New ideas come from an idea production function that depends on the number of people looking for new ideas as well as on the existing stock of ideas:

$$
\dot{A}=R f(A)=\beta R A^{\phi}
$$

where $R$ is the number of researchers and $\dot{A}$ is the flow of new ideas produced over time. In the long run, the stock of ideas is proportional to the number of researchers, which in turn is proportional to population. Thus, scale (e.g., the population of countries producing new ideas) matters for idea-based economies.

Assuming growth rates are constant - a reasonable approximation for the U.S. economy - Figure 2 summarizes the resulting growth accounting for the period 1950-2007. ${ }^{2}$ Importantly, this is not necessarily (and, we argue below, is not) the balanced-growth path.

Output per person, $y$, depends on four terms. First is the capital-output ratio, as in Solow (1956). Second is human capital per person, as in Denison (1962) and Lucas (1988). Third is research intensity, the investment rate that applies to the hunt for new ideas (here, researchers as a share of all workers), as emphasized by Romer (1990), Aghion and Howitt (1992), and Grossman and Helpman (1991). Fourth is the number of people in the economy, as in the semi-endogenous growth models of Jones (1995), Kortum (1997), and Segerstrom (1998). The last two terms, which correspond to TFP, constitute the stock of ideas. That stock is inferred from the "flow" of investment (research intensity and population).

\footnotetext{
${ }^{2}$ The key step is that, when $\dot{A} / A$ is constant at $g, A=(g / \beta) R^{\gamma}$, where $\gamma \equiv \frac{1}{1-\phi}$. It follows that $g \equiv \gamma \cdot \dot{R} / R$. In the data, $g=1.61 \%$ per year, $\dot{R} / R=4.2 \%$, implying $\gamma=0.38$. See Jones (2002) for further details on the model and derivation.
} 
Figure 2: Growth Accounting with Modern Growth Theory

$$
\begin{array}{ccccc}
y^{*} \approx\left(\frac{K}{Y}\right)^{\beta} \cdot h \cdot(\text { R\&D intensity })^{\gamma} \cdot L^{\gamma} \\
& \text { Solow } & \text { Lucas } & \text { Romer/AH/GH } & \mathrm{J} / \mathrm{K} / \mathrm{S} \\
2.0 & 0.0 & 0.4 & 1.2 & 0.4 \\
(100 \%) & (0 \%) & (20 \%) & (58 \%) & (21 \%)
\end{array}
$$

Growth rates and shares of overall growth show the contribution of each term in the equation to growth in U.S. GDP per hour from 1950 and 2007. See Jones (2002) for the methodology; a spreadsheet with the details is available online.

As the figure shows, the 2 percent annual growth in labor productivity largely came from rising human capital (0.4 p.p. per year, about 20 percent of the total) and rising research intensity in the advanced countries of the world (1.2 p.p., or 58 percent of the total). ${ }^{3}$

The contribution of human capital is easy to understand. The educational attainment of adults has been rising about one year per decade. A Mincerian return to education of 6 percent would then imply about 0.6 percentage points extra growth each year. In the accounting above, we use an index of labor quality from Jorgenson, Ho and Samuels (2013), which grows a bit more slowly. They estimate the educational contribution somewhat differently and include additional aspects of labor quality, such as demographics. But rising education is still the key driver in their index.

Figure 3 shows data on educational attainment by birth cohort rather than for the cross-section of workers. After 1950, the rise in education slows markedly and has ceased for the most recent cohorts. Nothing in the model requires this - educational attainment could rise with life expectancy and could even rise faster than life expectancy for a long time. However, educational attainment in the data does slow. In the future, one can reasonably expect a reduced contribution from education and, other things equal, slower income growth.

\footnotetext{
${ }^{3}$ The numbers differ somewhat from Jones (2002) because we are using a different index of human capital as well as a different time period.
} 
Figure 3: Educational Attainment by Birth Cohort

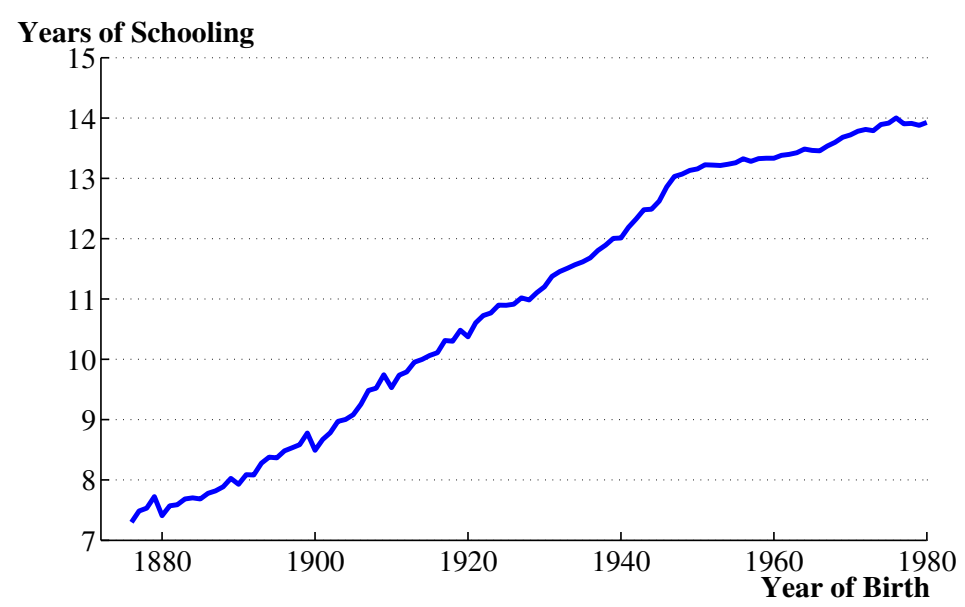

Source: Goldin and Katz (2008).

In sum, the accounting implies that growth over the past 50 years largely reflected transitory factors. The rise in educational attainment is already slowing, and the fraction of the labor force engaged in research cannot growth forever. Taken literally, only the scale-effects term - equal to $0.4 \mathrm{pp}$, or 21 percent of growth - generates sustainable long-run growth. Even this term could itself be slowing as fertility rates decline. We do not know when this long run will occur, but Figure 2 implies that future growth might be significantly lower than over the past half century.

\section{Diminishing Returns, Robots, and China}

Will growth, in fact, slow sharply in the coming decades? The accounting above depends on assumptions about the shape of the idea production function and the growth of inputs into research.

Specifically, recall that underlying the parameter $\gamma$ in Figure 2 is the production function for new ideas in equation (1) above, i.e. $\dot{A}=R f(A)=\beta R A^{\phi}$. Restricting $f(A)$ to be a power function is required for balanced growth but still allows flexibility. For example, the estimate of $\gamma=1 /(1-\phi)$ in Figure 2 implies that, historically, 
Figure 4: Alternative Futures?

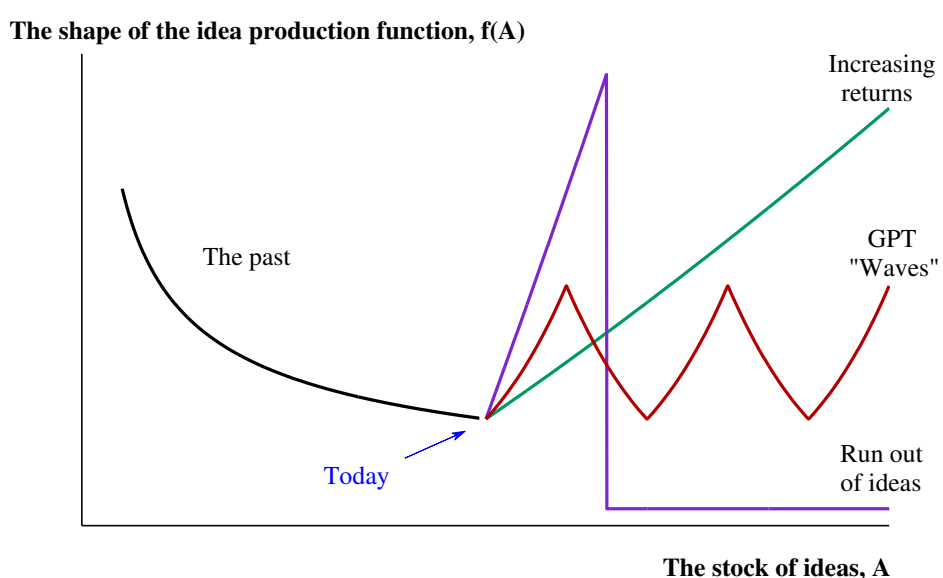

The shape of the idea production function for future levels of $A$ need not look like it has in the past.

$\phi<0$. That is, as more ideas are discovered, it can become harder and harder to discover the next new idea - a "fishing out" argument. Similarly, Cowen (2011) and Gordon (2012) argue that we may have "cherry picked" the most easily-discovered and important ideas already, perhaps implying slower growth in the future. ${ }^{4}$ Note that diminishing returns to the idea production function in equation (1) is consistent with balanced growth even if $\phi$ is negative. Though new ideas are harder to find, balanced growth can still occur because of exponential growth in the number of researchers, $R$. The difficulty of making proportional increments is offset by growing efforts to push the frontier forward. ${ }^{5}$

Of course, while restricting $f(A)$ to be a power-function is convenient and tractable, it might not be realistic. Moreover, the shape of $f(A)$ we have seen in the past might not be a reliable guide to the shape of $f(A)$ at higher (future) levels of $A$. For example, consider the alternative paths shown in Figure 4. Here, the idea production function of the past exhibits diminishing returns - it gets harder and harder to dis-

\footnotetext{
${ }^{4}$ As venture capitalist Peter Theil puts it, "We wanted flying cars, instead we got 140 characters."

${ }^{5}$ As an aside, consider the growth implications of the Great Recession. A reduction in research effort could have a persistent if not permanent effect on productivity. However, the slowdown in real $\mathrm{R} \& \mathrm{D}$ spending appears modest relative to previous recessions, and Fernald (2012) argues that productivity did slow, but prior to the Great Recession.
} 
cover new ideas. This path might continue into the future. Alternatively, we could reach an inflection point, after which it becomes easier and easier to discover new ideas. Or this could be true for awhile, but then maybe there are no additional new ideas to discover and $f(A)$ drops to zero. Or perhaps there are waves of good and bad periods corresponding to "general purpose technologies." Each alternative implies very different paths for future economic growth.

A second important consideration is growth in research inputs, $R$. In the accounting above, $R$ has been growing faster than population. This cannot continue forever, pointing towards slower future growth. But the number of relevant researchers might grow for a long time, and new research technologies might allow computers and robots to replace labor.

In terms of the number of researchers, developing economies are becoming richer and increasingly contribute to pushing the technological frontier forward. Figure 5 shows that South Korea and China exhibit particularly rapid growth in research spending — faster than even their already rapid GDP growth rates. China and India together have more than 1/3 of the world's population, so these economies could contribute substantially to future technological progress, far beyond what has probably been a negligible contribution over the last 50 years. Freeman (2009) points out that in 1978, China produced almost no Ph.D.'s in science and engineering, but by 2010, they were producing 25 percent more than the United States. How many future Thomas Edisons and Steve Jobses are there in China and India, waiting to realize their potential?

Even more speculatively, artificial intelligence and machine learning could allow computers and robots to increasingly replace labor in the production function for goods. Brynjolfsson and McAfee (2012) discuss this possibility. In standard growth models, it is quite easy to show that this can lead to a rising capital share - which we intriguingly already see in many countries since around 1980 (Karabarbounis and Neiman, 2013) - and to rising growth rates. In the limit, if capital can replace labor entirely, growth rates could explode, with incomes becoming infinite in finite time. 
Figure 5: R\&D Expenditures as a share of GDP

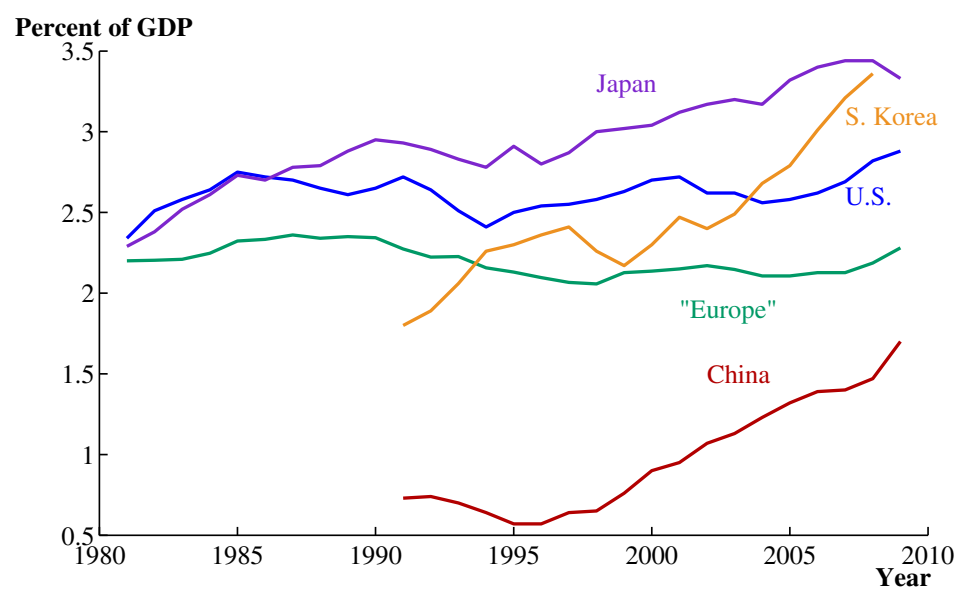

Source: NSF Science and Engineering Inicators, 2012, Appendix Table 04-43. "Europe" is the unweighted average of the numbers for France, Germany, and the United Kingdom.

For example, drawing on Zeira (1998), assume the production function is

$$
Y=A K^{\alpha}\left(L_{1}^{\beta_{1}} L_{2}^{\beta_{2}} \cdot \ldots \cdot L_{n}^{\beta_{n}}\right)^{1-\alpha} .
$$

Suppose that over time, it becomes possible to replace more and more of the labor tasks with capital. In this case, the capital share will rise, and since the growth rate of income per person is $1 /(1-$ capital share $) \times$ growth rate of $A$, the long-run growth rate will rise as well. ${ }^{6}$

\section{Conclusion}

Several recent papers project future growth using a neoclassical growth model. ${ }^{7}$ Byrne, Oliner and Sichel (2013), for example, analyze recent trends in semiconduc-

\footnotetext{
${ }^{6}$ Alternatively, consider the standard capital accumulation equation with Cobb-Douglas production: $\dot{K}=s A^{\sigma} K^{\alpha} L^{1-\alpha}-\delta K$. If the labor input can be replaced entirely by capital, this equation becomes $\dot{K} / K=s A^{\sigma}-\delta$. As knowledge accumulates, the growth rate of $K$ rises exponentially. Notice that the nonrivalry of ideas is at the heart of this result.

${ }^{7}$ see Fernald (2012), Byrne, Oliner and Sichel (2013), and Jorgenson, Ho and Samuels (2013) for recent examples with references.
} 
tors to obtain insight into the current shape of the idea production function and undertake projections. But modern growth theory suggests that such projections are at best a local approximation. The roughly constant growth of the past century and a half does not mean the U.S. is on a steady-state path, and the past - even the recent past - could be a poor guide to the future.

Our analysis suggests several key considerations. First, growth in educational attainment, developed-economy R\&D intensity, and population are all likely to be slower in the future than in the past. These factors point to slower growth in U.S. living standards. Second, a counterbalancing factor is the rise of China, India, and other emerging economies, which likely implies rapid growth in world researchers for at least the next several decades. Third, and more speculatively, the shape of the idea production function introduces a fundamental uncertainty into the future of growth. For example, the possibility that artificial intelligence will allow machines to replace workers to some extent could lead to higher growth in the future. Finally, other considerations we have not had space to address could impact future growth, including the rise in income inequality, climate change, and the systematic shift of the economy toward health care.

\section{References}

Aghion, Philippe and Peter Howitt, "A Model of Growth through Creative Destruction," Econometrica, March 1992, 60 (2), 323-351.

Brynjolfsson, Erik and Andrew McAfee, Race Against the Machine: How the Digital Revolution is Accelerating Innovation, Driving Productivity and Irreversibly Transforming Employment and the Economy, Digital Frontier Press, 2012.

Byrne, David M., Stephen D. Oliner, and Daniel E. Sichel, "Is the Information Technology Revolution Over?," International Productivity Monitor, Spring 2013, 25, $20-36$.

Cowen, Tyler, The Great Stagnation: How America Ate All The Low-Hanging Fruit of Modern History, Got Sick, and Will (Eventually) Feel Better: A Penguin eSpecial from Dutton, Penguin Group US, 2011. 
Denison, Edward F., The Sources of Economic Growth in the United States and the Alternatives Before Us, New York: Committee for Economic Development, 1962.

Fernald, John, "Productivity and potential output before, during, and after the Great Recession,” Working Paper Series 2012-18, Federal Reserve Bank of San Francisco 2012.

Freeman, Richard B., "What Does Global Expansion of Higher Education Mean for the US?," Working Paper 14962, National Bureau of Economic Research May 2009.

Goldin, Claudia and Lawrence F. Katz, The Race between Education and Technology, Belknap Press, 2008.

Gordon, Robert J., "Is U.S. Economic Growth Over? Faltering Innovation Confronts the Six Headwinds," Working Paper 18315, National Bureau of Economic Research August 2012.

Grossman, Gene M. and Elhanan Helpman, Innovation and Growth in the Global Economy, Cambridge, MA: MIT Press, 1991.

Jones, Charles I., "R\&D-Based Models of Economic Growth," Journal of Political Economy, August 1995, 103 (4), 759-784.

- , "Sources of U.S. Economic Growth in a World of Ideas," American Economic Review, March 2002, 92 (1), 220-239.

Jorgenson, Dale W., Mun S. Ho, and Jon D. Samuels, "Economic Growth in the Information Age: A Prototype Industry-Level Production Account for the United States, 1947-2010," July 2013. Manuscript.

Karabarbounis, Loukas and Brent Neiman, "The Global Decline of the Labor Share," Working Paper 19136, National Bureau of Economic Research June 2013.

Kortum, Samuel S., "Research, Patenting, and Technological Change," Econometrica, 1997, 65 (6), 1389-1419.

Lucas, Robert E., "On the Mechanics of Economic Development," Journal of Monetary Economics, 1988, 22 (1), 3-42.

Maddison, Angus, "Statistics on World Population, GDP and Per Capita GDP, 1-2006 AD," 2008. Downloaded on December 4, 2008 from http://www.ggdc.net/maddison/.

Romer, Paul M., “Endogenous Technological Change,” Journal of Political Economy, October 1990, 98 (5), S71-S102. 
Segerstrom, Paul, "Endogenous Growth Without Scale Effects," American Economic Review, December 1998, 88 (5), 1290-1310.

Solow, Robert M., "A Contribution to the Theory of Economic Growth," Quarterly Journal of Economics, February 1956, 70 (1), 65-94.

_ , "Technical Change and the Aggregate Production Function," Review of Economics and Statistics, August 1957, 39 (3), 312-320.

Zeira, Joseph, “Workers, Machines, And Economic Growth,” Quarterly Journal of Economics, November 1998, 113 (4), 1091-1117. 